\title{
A VIRTUALIZAÇÃO DO PROJETO DE PRODUTOS E PROCESSOS PRODUTIVOS E A INTERNET
}

\section{THE VIRTUALIZATION OF THE DESIGN OF PRODUCTS AND PROCESSES AND THE INTERNET}

\author{
Alexandre Reis Graeml ${ }^{1}$; Marie Anne Macadar² ${ }^{2}$ João Mário Csillag ${ }^{3}$ \\ ${ }^{1}$ Centro Universitário Positivo (Unicenp) / Universidade Tecnológica Federal do Paraná (UTFPR) \\ graeml@fulbrightweb.org \\ ${ }^{2}$ Universidade Estadual do Rio Grande do Sul (Uergs) marie-macadar@uergs.edu.br \\ ${ }^{3}$ Escola de Administração de Empresas de São Paulo (FGV-Eaesp) csillag@ @gvsp.br
}

\begin{abstract}
Resumo
Este artigo discute usos possíveis da Internet e outras ferramentas de TI na realização ou no suporte às atividades de desenvolvimento de projetos de novos produtos e processos. São apresentados os resultados comparados de duas pesquisas survey, contendo exatamente as mesmas questões, a que foram submetidas 105 indústrias de São Paulo. A primeira survey foi aplicada entre novembro de 2003 e fevereiro de 2004 e a segunda, entre novembro de 2006 e fevereiro de 2007. Os resultados obtidos evidenciam crescimento na utilização das técnicas discutidas, mas indicam também que existe um grande potencial inexplorado, principalmente nas empresas de menor porte.
\end{abstract}

Palavras-chave: Internet, prototipação virtual, realidade virtual, projeto colaborativo.

\section{Introdução}

O desenvolvimento mais ágil de produtos se tornou uma questão crítica para o sucesso em muitos setores do mercado, independentemente do produto em questão. Isto motivou o aparecimento de técnicas de engenharia simultânea, na década de 80, capazes de reduzir o tempo de ciclo, com base na sobreposição temporal de atividades de projeto, a ser executadas em paralelo, sempre que possível (FORD; STERMAN, 1999).

$\mathrm{Na}$ maioria dos casos de produtos industriais, protótipos precisam ser construídos antes de se considerar a produção em escala de um produto, para que este possa ser testado e operado, conforme observa Jons (1997). A construção dos inúmeros protótipos físicos a serem utilizados para testar e avaliar conceitos de projeto independentes uns dos outros, conforme lembra Boswell (1998), pode consumir muito tempo e apresentar custos elevados ou mesmo proibitivos. Normalmente também se requer que o produto tenha sido completamente projetado antes de poder 
ser construído, embora este paradigma comece a ser desafiado por empresas que percebem o quanto o tempo até o mercado (time to market) pode ser determinante do sucesso obtido e, é claro, que conseguem fazer alguma coisa para reduzi-lo ou eliminá-lo. Estas restrições físicas dificultam a realização, em paralelo, de diversas tarefas de projeto, de teste e aceitação de um produto, conforme preconizado pela engenharia simultânea.

Em face do exposto, o objetivo deste artigo é discutir a possibilidade de virtualização de atividades de projeto e o suporte oferecido pela Internet e outras ferramentas de TI para tal, assim como identificar o quanto as empresas industriais de São Paulo têm se valido desses recursos tecnológicos com o intuito de melhorar a forma como desenvolvem produtos e processos produtivos. Os autores acreditam que esses recursos tecnológicos podem representar um facilitador para a implantação da engenharia simultânea e uma forma de tentar garantir que os projetos sejam desenvolvidos de modo a se fazer certo na primeira vez, quando se partir para a construção do produto físico real.

\section{Ambientes virtuais e o suporte que proporcionam às atividades de projeto}

Os ambientes virtuais, que podem possibilitar a virtualização de atividades de projeto, se originaram da convergência dos avanços da tecnologia de eletrônica digital dos computadores com os avanços na tecnologia de apresentação visual (Jons, 1997). Inicialmente, as atividades de desenho técnico, que envolviam papel, lápis e prancheta migraram para o computador para se beneficiar das possibilidades de cortar e colar (cut and paste), gravar, alterar e imprimir versões intermediárias ou finais de projetos, sempre que se desejasse, com pouca necessidade de retrabalho.

As ferramentas de CAD (Computer Aided Design) em duas dimensões representaram para o desenhista técnico o mesmo que os processadores de texto para o datilógrafo: uma forma de realizar o trabalho de forma mais eficiente. Contudo, quando as ferramentas de CAD passaram a oferecer recursos tridimensionais (CAD 3D), elas permitiram um salto qualitativo sem precedentes e possibilitaram que simulações virtuais substituíssem ensaios físicos, antes imprescindíveis a qualquer projeto de produto. Na verdade, conforme lembram Duarte e Barberato (2003), o CAD tridimensional é um processo de desenvolvimento de projeto totalmente diferente do que se fazia antes: no modelador sólido, a construção do projeto se faz por meio de adição dos itens necessários, incluindo suas principais informações, como dimensões, tolerâncias e especificações de materiais, que ficam agregadas ao modelo eletrônico do projeto.

Outra característica dos projetos em CAD que a princípio não apresentava grande valor, mas que, com a ampliação da conectividade eletrônica proporcionada por redes de computadores/telecomunicações e pela própria Internet, acabou assumindo grande relevância, é a virtualização 
da atividade de desenho. A desmaterialização do desenho técnico pode representar um passo fundamental para permitir o compartilhamento da informação e a realização de projetos de engenharia colaborativa, envolvendo projetistas que não precisam, necessariamente, encontrar-se fisicamente próximos uns dos outros para a realização do trabalho.

É cada vez mais fácil criar imagens gráficas realistas e transmiti-las para que possam ser rapidamente apresentadas com qualidade próxima a de uma fotografia, podendo ser utilizadas por outras pessoas ou equipes envolvidas em um projeto maior. Os principais desenvolvimentos nesta área estão ligados a: projeto baseado em simulação (simulation based design), prototipação virtual (virtual prototyping), realidade virtual (virtual reality) e projeto colaborativo à distância, que serão discutidos a seguir. Antes disto, contudo, merece destaque a possibilidade de uso dos recursos da Internet para a geração e aprimoramento de novas idéias, com o potencial de se transformarem na especificação de novos produtos.

\subsection{Ambientes virtuais e o suporte que proporcionam à geração de idéias}

Produtos novos surgem de novas idéias, de modo que uma etapa importante do processo de desenvolvimento consiste na geração e aprimoramento de idéias, que possam ser convertidas em produtos com interesse mercadológico. Ozer (2003) lembra que inúmeros experimentos já demonstraram que sessões de geração de idéias on-line geram idéias de melhor qualidade e mais originais do que as obtidas em sessões convencionais. Além disso, na opinião deste autor, os participantes em atividades de geração de idéias ficam muito mais satisfeitos quando elas são realizadas por meio de encontros "virtuais", uma vez que a Internet é capaz de disponibilizar a plataforma eletrônica ideal para a geração conjunta de idéias por indivíduos eventualmente separados fisicamente.

No processo de geração de idéias, de uma forma virtual, pode-se envolver a equipe de desenvolvimento, mas também fornecedores, clientes e até consumidores, já que, eliminados os custos de deslocamento, o esforço coletivo se restringe ao tempo efetivamente utilizado para a atividade criativa. Seguindo esta linha de pesamento, Thomke e Hippel (2002) acreditam que as atividades de pesquisa e desenvolvimento (P\&D) não precisam continuar seguindo os procedimentos dispendiosos e imprecisos do passado. As empresas podem, segundo estes autores, envolver os seus consumidores no desenvolvimento dos produtos, fornecendo a eles as ferramentas necessárias para que estes contribuam com as atividades de projeto. Em geral, quando são convidadas a expressar sua opinião e participar do desenvolvimento do projeto com suas idéias, as pessoas se sentem como se fizessem parte da equipe de desenvolvimento. A própria aceitação do produto, depois de disponibilizado ao mercado, é mais rápida, além do nível de comprometimento 
com a marca se tornar maior, conforme já percebia McKenna (1995), em uma época em que a Internet ainda tinha uso empresarial modesto, impedindo que o autor enxergasse nela, naquele momento, o canal perfeito para esse tipo de iniciativa.

\subsection{Projeto baseado em simulação e prototipação virtual}

Os benefícios da engenharia simultânea são muitos, mas as técnicas envolvidas exigem um enorme esforço de engenharia e apresentam capacidade limitada de análises de custo para todo o ciclo de vida do projeto, para possibilitar a integração e otimização multifuncionais e para melhorar a colaboração de equipes dispersas geograficamente, conforme observado por Goldin, Venneri e Noor (1998).

Para compensar essas deficiências da engenharia simultânea, muitas empresas têm procurado desenvolver abordagens de projeto baseado em simulação (Simulation Based Design $S B D)$, capazes de simular todo o ciclo de vida do projeto, desde o desenvolvimento do conceito até o projeto detalhado, a geração de protótipos, os testes, a operação, a manutenção e o descarte dos produtos no fim da sua vida útil, eliminando a necessidade de criação de um protótipo físico ou postergando-a.

Goldin, Venneri e Noor (1998) consideram que, ao se envolver com o ambiente de projeto virtual, os engenheiros são capazes de criar ou modificar seus projetos em tempo real, observando os efeitos das suas ações sobre o projeto como um todo, imediatamente.

A prototipação virtual envolve o desenvolvimento e "utilização" em um ambiente virtual, totalmente baseado em computador, de um produto que ainda não existe fisicamente. De acordo com Deviprasad (2003), a prototipação para projeto usando ambientes virtuais se tornou um campo de pesquisa importante, nos últimos anos. Este autor cita dezenas de artigos na área de engenharia mecânica que discutem a utilização de técnicas de prototipação virtual, associadas à realidade virtual, para tornar o projeto de peças, produtos e ferramentas mais rápido, menos dispendioso e de melhor qualidade. Ozer (2003) também menciona estudos empíricos que mostram que protótipos virtuais podem ser tão eficazes quanto os tradicionais protótipos físicos.

A solução ideal deve, na opinião de Jons (1997), libertar o projeto das restrições físicas impostas pela necessidade de um protótipo físico. Assim, um protótipo virtual deve permitir:

- O projeto do produto, com boa visualização da sua aparência e boa percepção da funcionalidade;

- A construção do produto (protótipo virtual) sem as restrições e custos envolvidos na construção do protótipo físico;

- O teste do produto (protótipo virtual) para verificar seu futuro desempenho; 
- A operação do produto (protótipo virtual) em um ambiente realista e com controle humano;

Outra característica não mencionada por Jons (1997), mas também de grande importância é:

- A possibilidade de transferência eletrônica do protótipo virtual, permitindo o trabalho simultâneo de equipes de desenvolvimento geograficamente dispersas.

Boswell (1998) considera que novas tecnologias, dentre as quais a prototipação digital, estão revolucionando a forma como produtos são projetados, oferecendo flexibilidade sem precedentes, por meio da eficiente integração de dados e de uma abordagem de engenharia mais simultânea.

Protótipos virtuais realizados em $\mathrm{CAD}$, com recursos de $3 \mathrm{D}$, podem ser facilmente montados e desmontados virtualmente, permitindo estudos muito mais detalhados, repetidos quantas vezes se julgar necessário.

A rapidez com que podem ser realizadas alterações nos protótipos virtuais e o baixo custo dessas alterações estimulam a realização de mais ensaios, com configurações alternativas das peças sendo projetadas. Isto permite que produtos de melhor qualidade demorem menos tempo para ser desenvolvidos e colocados no mercado.

Por todos esses motivos, a prototipação digital parece ser uma opção interessante para empresas que precisam desenvolver peças complexas, que devem se ajustar perfeitamente a outras partes, desenvolvidas por outras equipes de projeto. $\mathrm{O}$ fato de os protótipos digitais deixarem de ser produtos físicos e se transformarem em produtos de informação lhes confere as "qualidades mágicas" que os tornam perfeitos para a Internet (GEOFFRION e KRISHNAN, 2001). Deixam de existir as restrições físicas que antes dificultavam o trabalho coletivo, compartilhado e simultâneo, tão desejados para este tipo de atividade, já que, depois que o protótipo virtual é criado, ou mesmo durante o seu desenvolvimento, ele pode ser disponibilizado eletronicamente a todos os membros de uma equipe de projeto, incluindo o pessoal de chão-de-fábrica, os projetistas e os fabricantes das máquinas (BAPAT, 2002).

\subsection{Realidade virtual}

Boswell (1998) considera que o estudo de ambientes virtuais, por meio de uma experiência sensorial (em que um participante humano seja inserido dentro de uma simulação de computador que proporcione sensações visuais, auditivas e táteis), pode representar um suporte importante para projetos que envolvem prototipação digital. A realidade virtual contribui, na visão de Duarte e Barberato (2003), para a identificação antecipada de dificuldades existentes em projetos criados em sistemas CAD 3D, possibilitando a redução do ciclo de desenvolvimento integrado do projeto. Ottosson (2002) também desfruta desta opinião e afirma que, utilizando realidade virtual, os usuários 
podem testar produtos "virtualmente" e treinar a sua utilização antes mesmo de os produtos existirem de verdade, o que pode melhorar o projeto, no que tange à usabilidade e à ergonomia. Desta forma, é possível aos clientes e usuários assumir uma postura mais ativa no desenvolvimento de novos produtos, influenciando o resultado do projeto.

Embora a maioria das aplicações práticas de realidade virtual ainda se concentre no setor de entretenimento, há boas perspectivas para sua utilização no projeto e até no buy-in pelos clientes em potencial de produtos que ainda não saíram sequer da prancheta do desenvolvedor, como aconteceu no caso da Embraer, que adotou uma estratégia de envolvimento precoce do cliente para conseguir vender inúmeras aeronaves a clientes que tiveram acesso apenas ao projeto do ERJ-170, que lhes foi apresentado por meio de sofisticados recursos de simulação e realidade virtual (ERA, 2002; SHIFRIN, 2004).

\subsection{Projeto colaborativo à distância}

A prototipação dinâmica e o uso de simulações a partir dos protótipos virtuais gerados têm permitido que equipes de projeto espacialmente dispersas trabalhem simultaneamente no mesmo projeto. Para isto, são utilizadas ferramentas que possibilitam a gestão do trabalho colaborativo realizado por pessoas que podem tanto dividir a mesma sala como estar separadas umas das outras por milhares de quilômetros. Integrantes de uma equipe de trabalho virtual podem se comunicar uns com os outros de forma bastante efetiva e trocar documentos, projetos de produtos e software por meio da Internet, conforme lembra Ozer (2003). Além disso, o trabalho virtual permite às empresas lançar mão de seus melhores recursos, com relação a conhecimentos específicos, independentemente da sua localização física (KIRKMAN et al., 2002). A integração das contribuições de todos os participantes do projeto é agregada em um modelo mestre, que passa a estar disponível para o grupo, por meio de representações visuais e do compartilhamento de dados que se façam necessários para o bom andamento do trabalho coletivo.

Boas ferramentas para o trabalho colaborativo e para a comunicação eficaz entre as diversas partes envolvidas no desenvolvimento de um projeto são raras. Um aspecto que ainda exige atenção é a criação de métodos que permitam o gerenciamento de objetivos conflitantes das diversas equipes de projeto que trabalham em paralelo e de métodos capazes de apoiar as decisões conceituais que precisam ser tomadas já nos primeiros estágios do projeto, mas que comprometem todo o curso de ação posterior. Galina e Santos (1998) consideram o suporte computacional para trabalho cooperativo (Computer-Supported Cooperative Work - CSCW) uma área de pesquisa fundamental para melhorar a possibilidade de interação cooperativa entre os membros de uma equipe de projeto. A CSCW, ao se preocupar com a comunicação e cooperação/colaboração entre as 
pessoas e com a coordenação das atividades em grupo, torna-se uma ferramenta útil ao suporte de iniciativas de engenharia simultânea.

Ainda assim, o processo de tomada de decisão consensual não ocorre facilmente pelo uso dos canais disponibilizados pelas novas tecnologias. Na opinião de Rheingold (2000), as conversas on-line tendem a divergir, ramificar e perder o foco, ao invés de convergir. Ele acredita que uma conferência por computador é mais útil para permitir que todas as opiniões sejam apresentadas do que para se criar consenso sobre o caminho a seguir. Nessa mesma linha, Lebkowsky (1999) racionaliza sobre os motivos pelos quais a "democracia on-line" é tão difícil de ser atingida. Outro pesquisador que demonstra ceticismo com relação à utilização exclusiva dos meios eletrônicos como forma de comunicação de equipes de projeto é Ozer (2003), para quem um certo grau de contato face-a-face é essencial à geração de confiança mútua em um grupo de trabalho virtual.

Ainda assim, Kirkman et al. (2002) demonstram entusiasmo com as novas oportunidades de se criar e gerenciar equipes virtuais, as quais se tornaram possíveis em conseqüência dos avanços nas tecnologias de comunicação/informação.

\subsection{Exemplos de implementações bem sucedidas de virtualização das atividades de projeto encontrados na literatura}

Um setor que tem investido pesado na utilização de ferramentas para possibilitar o projeto virtual dos seus produtos é a indústria automotiva. Boswell (1998) cita as iniciativas de engenharia simultânea da Ford e o programa de inovação digital da Mazda. Essas empresas acreditam que o projeto virtual permite melhor visualização e interação holística dos seus engenheiros com o projeto, facilitando a comunicação e levando à redução dos custos de desenvolvimento e do tempo até o mercado. A Daimler-Chrysler, por sua vez, dedicou mais de cinco anos à criação de um laboratório de testes virtuais e modelos matemáticos baseados em dados de testes físicos, capazes de simular corretamente o que aconteceria em um experimento real. Agora, os engenheiros da empresa, que desenvolvem as plataformas dos automóveis Mercedes-Benz, podem utilizar sofisticadas ferramentas computacionais para desenvolver e testar protótipos virtuais dos novos carros da marca (MORAN, 2003).

No Brasil, projetistas de montadoras de automóveis entrevistados por Duarte e Barberato (2003) acreditam que a virtualização das atividades de projeto tem proporcionado condições para a intensificação de parcerias estratégicas. Esses profissionais consideram que as novas tecnologias (particularmente o CAD 3D) representam um dos fatores principais de estímulo à aplicação de engenharia simultânea no desenvolvimento conjunto de novos produtos com parceiros de todo o mundo, independente da distância física. Reforçando esta percepção, Pires e Prates (2003) 
consideram que a adoção da engenharia simultânea sofreu forte estímulo a partir do crescente uso da Internet, intranet e outras ferramentas de comunicação reais e virtuais. Uma pesquisa realizada por esses autores com empresas industriais do Paraná detectou um aumento na utilização dessa técnica, que era adotada por 32\% dos respondentes em 1994 e por 54\% em 2000. Duarte e Barberato (2003) constataram ainda que algumas subsidiárias brasileiras de empresas européias e norte-americanas do setor automobilístico passaram a participar mais intensamente do desenvolvimento de novos veículos, sua adaptação ao mercado da América Latina (tropicalização do produto) e, de forma ainda mais expressiva, do desenvolvimento de ferramentas para a produção.

A marinha norte-americana também está utilizando protótipos virtuais e realidade virtual para construir navios de guerra. De acordo com Kenyon (2004), a conversão dos dados de projeto em imagens tridimensionais, por meio de sistemas de computador de última geração, permite que os engenheiros identifiquem pontos potencialmente problemáticos na carcaça de um navio que está sendo desenvolvido, podendo compartilhar a informação com outras equipes de projeto ao redor do país. Isto demonstra que a virtualização tem contribuído também para projetos mais colaborativos, em que os gerentes e patrocinadores do programa se envolvem mais profundamente com o processo de projeto, desde os primeiros estágios da sua execução. O Centro para Visualização de Conceitos (Center for Concept Visualization), criado pela marinha dos EUA em Maryland, ainda de acordo com Kenyon (2004), possui uma sala de projeções em que os visitantes utilizam óculos especiais, que criam um efeito tridimensional completo, para a análise dos projetos em desenvolvimento. $\mathrm{O}$ objetivo do sistema é permitir que os projetistas tomem melhores decisões mais cedo no processo de desenvolvimento das embarcações, detectando eventuais problemas antes que qualquer parte física seja confeccionada no estaleiro.

Mas o exemplo mais conhecido de projeto bem sucedido baseado em protótipos digitais, contudo, é o do Boeing 777. O programa de desenvolvimento desse avião durou menos de 4 anos, desde o seu início até a primeira decolagem. Equipes multifuncionais espalhadas ao redor do mundo se envolveram simultaneamente na criação dos protótipos virtuais. Apenas o nariz do 777 precisou de um mockup físico, para permitir a verificação de aspectos críticos da fiação elétrica. Todas as demais partes foram completamente projetadas de forma virtual, sem nenhuma simulação física anterior à montagem da primeira aeronave (BOSWELL, 1998). Ford e Sterman (1999) ressaltam que a Boeing estabeleceu uma rede de equipes de desenvolvimento composta por mais de 4000 engenheiros encarregados do projeto simultâneo das 130 mil peças que compõem o avião. Jons (1997) complementa, informando que foram mais de 3 trilhões de bytes de informação manipulados por 8 mainframes, utilizados para suportar o projeto e suas 20 mil releases.

Embora o projeto do Boeing 777 tenha se utilizado intensamente de comunicação eletrônica, a empresa tomou o cuidado de reunir membros da futura equipe virtual para trabalhar fisicamente 
juntos nos Estados Unidos, por um período de até 18 meses. Isto foi importante para que os envolvidos aprendessem a trabalhar com o sistema de gestão de projetos da empresa, compartilhassem experiências e desenvolvessem um nível de confiança mútua que permitisse superar os obstáculos impostos pela separação física, nos estágios subseqüentes do projeto. Como já foi observado, Ozer (2003) salienta a importância deste cuidado, ressaltando que existe evidência empírica suficiente de que a comunicação eletrônica pode ser pouco eficiente, se não for complementada com algum grau de comunicação face-a-face, o que justificaria a preocupação da Boeing com o contato pessoal em determinadas circunstâncias.

Kroo (1996) salienta que apesar de o Boeing 777 ter sido completamente projetado, vôos terem sido simulados e peças submetidas (virtualmente) a manutenção antes que qualquer componente do avião fosse fisicamente produzido, a experiência da Boeing com o projeto baseado em computador de aeronaves demonstra o quanto ainda se está distante de explorar toda a potencialidade das ferramentas de projeto em ambiente virtual. Quando a equipe de projeto terminou de conceber o primeiro protótipo virtual do 777 , as decisões que já haviam sido tomadas comprometiam mais de $70 \%$ dos custos do ciclo de vida do produto. Ainda segundo Kroo, o formato aerodinâmico da asa, por exemplo, foi projetado pelo grupo de aerodinâmica em alta velocidade, isoladamente, tomando por base apenas considerações heurísticas relacionadas ao desempenho das estruturas em baixas velocidades. Nenhuma contribuição foi obtida, nessa fase, do grupo de estabilidade e controle. Por isso, esse autor considera que um dos grandes benefícios potenciais ainda não concretizados da realização de projetos baseados em simulação é a possibilidade de incorporar, desde os primeiros estágios do desenvolvimento do projeto, requisitos e objetivos multidisciplinares e inter-departamentais, nos quais os protótipos virtuais possam fazer diferença significativa. É o que a Boeing espera conseguir com o projeto do seu novo avião, o 7E7 Dreamliner.

Depois do aprendizado com o projeto virtual do 777, a Boeing pretende modelar virtualmente todos os componentes do 7E7 Dreamliner, a ser lançado no mercado em 2008. Para isso, a empresa pretende simular processos de usinagem e estampagem, atividades da linha de montagem, procedimentos de manutenção e treinamento de equipes. Tudo isto antes de o primeiro avião real passar pela linha de montagem, o qual, por sinal, não será um protótipo, mas um exemplar completamente funcional a ser entregue a um cliente, para colocação imediata em operação regular (CARMODY, 2003). De acordo com Kevin Fowler, diretor de integração de processos da Boeing para o 7E7, em entrevista a Carmody (2003), os mecânicos e funcionários da linha de montagem vão construir os primeiros aviões em um ambiente virtual, para reduzir a curva de aprendizado, servindo de treinamento para o momento de começar a produzir as aeronaves de verdade. 
Apresentados os casos de algumas montadoras de automóveis, da marinha norte-americana e da Boeing, que estão na vanguarda da virtualização do projeto de produtos e processos produtivos, interessa aos autores deste artigo descortinar a situação das empresas industriais brasileiras, no geral. Apesar de ter sido submetido a um choque de produtividade nos últimos anos, na tentativa de se manter competitivo em um mercado globalizado, o setor industrial brasileiro é considerado por muitos analistas como conservador no que tange a mudanças nos processos produtivos. $\mathrm{O}$ setor assimila lentamente novas tecnologias, processos e rotinas, principalmente quando não dizem respeito à sua competência essencial. Antes de apresentar os resultados da pesquisa e de analisá-los, contudo, faz-se mister descrever a metodologia utilizada neste estudo, na expectativa de fornecer ao leitor informações sobre a sua propriedade e acuracidade.

\section{Procedimentos metodológicos}

O projeto de pesquisa que originou os dados analisados neste artigo foi desenvolvido com o objetivo de ampliar o entendimento da forma como as empresas industriais brasileiras utilizam a Internet para suportar suas estratégias e práticas de negócios.

Este artigo discute usos possíveis da Internet e outras ferramentas de TI na realização ou no suporte às atividades de desenvolvimento de projetos de novos produtos e processos, a partir da revisão da literatura sobre o assunto.

Foram coletados dados de 105 empresas industriais de São Paulo, constantes do cadastro da FIESP, que foi parceira deste projeto, em duas ocasiões:

- de novembro de 2003 a fevereiro de 2004

- de novembro de 2006 a fevereiro de 2007

A primeira survey, realizada por meio de uma mensagem eletrônica enviada a todos os endereços de e-mail válidos constantes da base de dados da FIESP, gerou uma amostra de conveniência contendo as respostas de mais de 600 empresas industriais, que forneceram informações sobre o impacto da Internet sobre diversas de suas atividades (cerca de 8\% das cerca de 7.800 mensagens que se acredita terem sido entregues corretamente aos destinatários). Naquele momento, foram realizados diversos procedimentos para garantir que a amostra fosse representativa da população, uma vez que o fato de se estar utilizando a própria Internet para se pesquisar sobre o uso que as empresas faziam dela era, por si só, um potencial gerador de viés. Os autores se acautelaram contactando outras 100 empresas por telefone. Metade delas foi selecionada entre as empresas da base de dados que, embora tivessem um e-mail válido, não haviam respondido à pesquisa. A outra metade consistiu de empresas que não dispunham de endereço de e-mail indicado na base de dados. Quase a totalidade dos não-respondentes entre as empresas que tinham e-mail 
indicado na base de dados alegou ter ignorado o convite por falta de tempo para dedicar à pesquisa, o que não constitui um indicador de possível viés, para os fins da pesquisa. Dentre as empresas que não tinham e-mail na base de dados, ficou constatado no contato telefônico que apenas uma empresa com mais de 50 funcionários de fato não possuía endereço de e-mail, de modo que, se houve algum viés pela aceitação da amostra de conveniência, ele ocorreu para as empresas pequenas, dentre as quais, de fato, diversas das empresas contactadas por telefone (aprox. 25\%) afirmaram não dispor de um endereço eletrônico.

Para a amostra de conveniência obtida na pesquisa de 2003/2004, foram realizadas ainda comparações com a população, com base nos dados demográficos existentes na base de dados da FIESP. Não foi detectada nenhuma evidência de dissociação entre amostra e população. Ao contrário, testes $\chi^{2}$ realizados com base na localização das empresas (região do estado de São Paulo) e porte revelaram-se bastante favoráveis, indicando um padrão de composição da amostra muito similar ao da população para as variáveis estudadas.

A segunda survey também foi realizada de forma eletrônica, mas, ao invés de se enviar uma mensagem contendo o formulário a ser preenchido em anexo a todas as empresas da base de dados, apenas as empresas que haviam participado da survey anterior foram convidadas a visitar a página eletrônica da pesquisa. Nela encontrava-se o formulário de investigação, hospedado no servidor da instituição de ensino que apoiou o estudo em conjunto com a FIESP. Foram obtidas 105 respostas válidas, que correspondem a $16 \%$ da população, representada pela amostra de conveniência anterior.

Embora, novamente, a amostra não seja probabilística, já que consistiu apenas dos elementos da população que se sujeitaram a participar da pesquisa, testes estatísticos não revelaram incompatibilidade entre amostra e população, com relação ao percentual de empresas dos diversos portes. Não foi realizado teste estatístico com relação à localização, em virtude do pequeno tamanho da amostra face ao número relativamente elevado de possíveis localizações.

As duas surveys consistiram no mesmo conjunto de questões, enunciadas de forma a permitir respostas a partir de um conjunto pré-definido de alternativas, apresentadas em uma escala inspirada na escala Likert, mas adotando níveis (ou intensidades) de mudança ou graus de utilização, dependendo do caso.

Para marcar a sua resposta, o respondente precisava apenas clicar sobre uma das opções disponibilizadas por meio de um menu drop-down, conforme mostrado na Figura 1, a seguir.

O questionário foi pré-testado com relação ao seu conteúdo, tendo sido apresentado a um grupo de executivos que estavam realizando um curso de extensão universitária, antes da sua primeira utilização, em 2003/2004. Esses executivos deram uma contribuição importante no sentido 
de tornar as perguntas mais acessíveis e compreensíveis para os reais participantes da pesquisa, em um estágio posterior.

Figura 1 - Menus drop-down adotados nos formulários eletrônicos das surveys

\begin{tabular}{|l|}
\hline Escolha uma alternativa.... \\
\hline Escolha uma alternativa... \\
\hline Não sei responder \\
Não se aplica \\
\hline Sem nenhuma mudança \\
Mudança muito pequena \\
Mudança pequena \\
Mudança razoável \\
Mudanças significativa \\
Mudança muito significativa \\
Mudança radical \\
\hline
\end{tabular}

\begin{tabular}{|l|}
\hline Escolha uma alternativa.... \\
\hline Escolha uma alternativa... \\
\hline Não sei responder \\
Não se aplica \\
\hline Não vamos usar (próx. 3 anos) \\
Vamos usar em até 3 anos \\
Usamos muito pouco \\
Usamos pouco \\
Usamos moderadamente \\
Usamos muito \\
É fundamental para o negócio \\
\hline
\end{tabular}

A próxima seção apresenta os resultados obtidos para as seguintes perguntas, constantes do questionário apresentado às empresas nas duas ocasiões (nov2003/fev2004 e nov2006/ fev2007):

- A Internet e outras TI causaram mudanças na forma como sua empresa executa o desenvolvimento de projetos de produtos, ao longo dos últimos 3 anos?

- A Internet e outras TI causaram mudanças na forma como sua empresa executa o desenvolvimento de projetos de processos produtivos, ao longo dos últimos 3 anos?

- Com que intensidade a empresa utiliza abordagens de projeto que visam a simular em computador as diversas etapas do ciclo de vida de um projeto?

- Com que intensidade a empresa utiliza protótipos virtuais no desenvolvimento de produtos que ainda não existem fisicamente, em um ambiente digital virtual baseado em computador?

- Com que intensidade a empresa utiliza ambientes virtuais permitindo uma experiência sensorial em que um participante humano é inserido em uma simulação de computador que proporciona sensações visuais, auditivas e táteis?

- Com que intensidade a empresa utiliza ferramentas que permitem a realização e a gestão do trabalho colaborativo de uma equipe de pessoas que se encontram fisicamente dispersas?

Foram desprezadas as respostas dadas pelas demais empresas que participaram da survey de 2003/2004, concentrando-se a apresentação dos dados e a análise sobre as respostas proporcionadas pelas 105 empresas que colaboraram em ambos os momentos. Isto foi feito porque, embora a coleta de dados pontual em duas datas distintas não seja suficiente para se estabelecer a longitudinalidade do estudo, ela oferece pistas sobre possíveis tendências, que podem ser melhor estudadas, posteriormente, adotando-se outras metodologias mais adequadas para tal fim.

Outro argumento que reforça a opção por se trabalhar apenas os dados das 105 empresas que participaram em ambas as ocasiões é que, para 88 dessas empresas, o respondente foi exatamente a 
mesma pessoa em 2003/204 e agora, em 2006/2007. Em outros 11 casos não foi possível identificar se isto aconteceu e apenas 6 empresas enviaram dados seguramente reportados por pessoas distintas nas duas vezes. O fato de os mesmos respondentes terem se encarregado de responder o questionário em 2003/2004 e em 2006/2007 melhora a comparabilidade das duas amostras, já que surveys tratam de percepções, que podem variar de um indivíduo para outro, ainda que dentro da mesma empresa e deparados com a mesma realidade.

\section{Discussão dos resultados da pesquisa}

Ao serem questionados sobre se a Internet e outras TI causaram mudanças na forma como a empresa desenvolve projetos de produtos, ao longo dos últimos 3 anos, as empresas responderam conforme mostrado no gráfico da Figura 2.

Como as diversas figuras apresentadas ao longo do texto adotam a mesma lógica construtiva, vale a pena explicar como foram elaborados esses gráficos. O eixo das ordenadas apresenta, de forma discriminada, os dados relacionados às empresas de diversos portes. Esta discriminação é realizada porque os autores já perceberam em estudos anteriores, assim como diversos outros pesquisadores da área, que o porte é um fator importante de variação no comportamento das empresas com relação à adoção de tecnologias mais sofisticadas. Isto ficará evidente ao se observar as Figuras 2 a 6, em que, salvo em circunstâncias excepcionais, as empresas maiores adotam as diversas técnicas e ferramentas em intensidades percentualmente superiores às empresas menores. A categoria superior do eixo das ordenadas ("geral") agrega as quantidades relacionadas a todos os portes de empresa, representando a informação sem discriminação em função do porte. Os números contidos dentro de cada uma das caixinhas que compõem as diversas barras horizontais indicam a quantidade absoluta de empresas do referido porte que ofereceram determinada resposta à questão, de acordo com a indicação na legenda apresentada embaixo do gráfico. Mas, como a quantidade de empresas dos diferentes portes não se mantém constante, já que há muito mais empresas pequenas do que grandes na amostra (e também na população), adotou-se uma escala percentual no eixo das abscissas, para melhorar a comparabilidade das características de adoção de uma determinada ferramenta, técnica ou comportamento por empresas dos variados portes.

Voltando à análise da Figura 2, percebe-se que, contradizendo um pouco a regra geral que se afirmou existir acima, pela qual empresas maiores fazem uso mais intensivo de novas tecnologias, as empresas que percentualmente afirmam ter sido submetidas às maiores mudanças em virtude da utilização da Internet e outras TI para o projeto de produtos foram as empresas relativamente pequenas, na faixa de 50 a 100 funcionários. Outro fato interessante de se observar, neste caso, é que dentre as empresas realmente pequenas (menos de 50 funcionários) parece ter havido uma 
retração no efeito da Internet sobre as atividades de projeto de produtos. É impossível afirmar, a partir de um estudo meramente quantitativo, baseado exclusivamente em surveys, o motivo pelo qual isto se deu. Como a survey trata da percepção do respondente, que normalmente envolve componentes mais e menos racionais, pode ter ocorrido que, em um momento mais distante no tempo (2003/2004), em que a Internet ainda representava novidade para alguns, o deslumbramento com o seu potencial tenha impedido uma visão mais realista do que de fato estava acontecendo. Outras pesquisas são, contudo, necessárias para se esclarecer este ponto.

Figura 2 - Percepção de mudança ocasionada pela Internet e outras TI no projeto de produtos

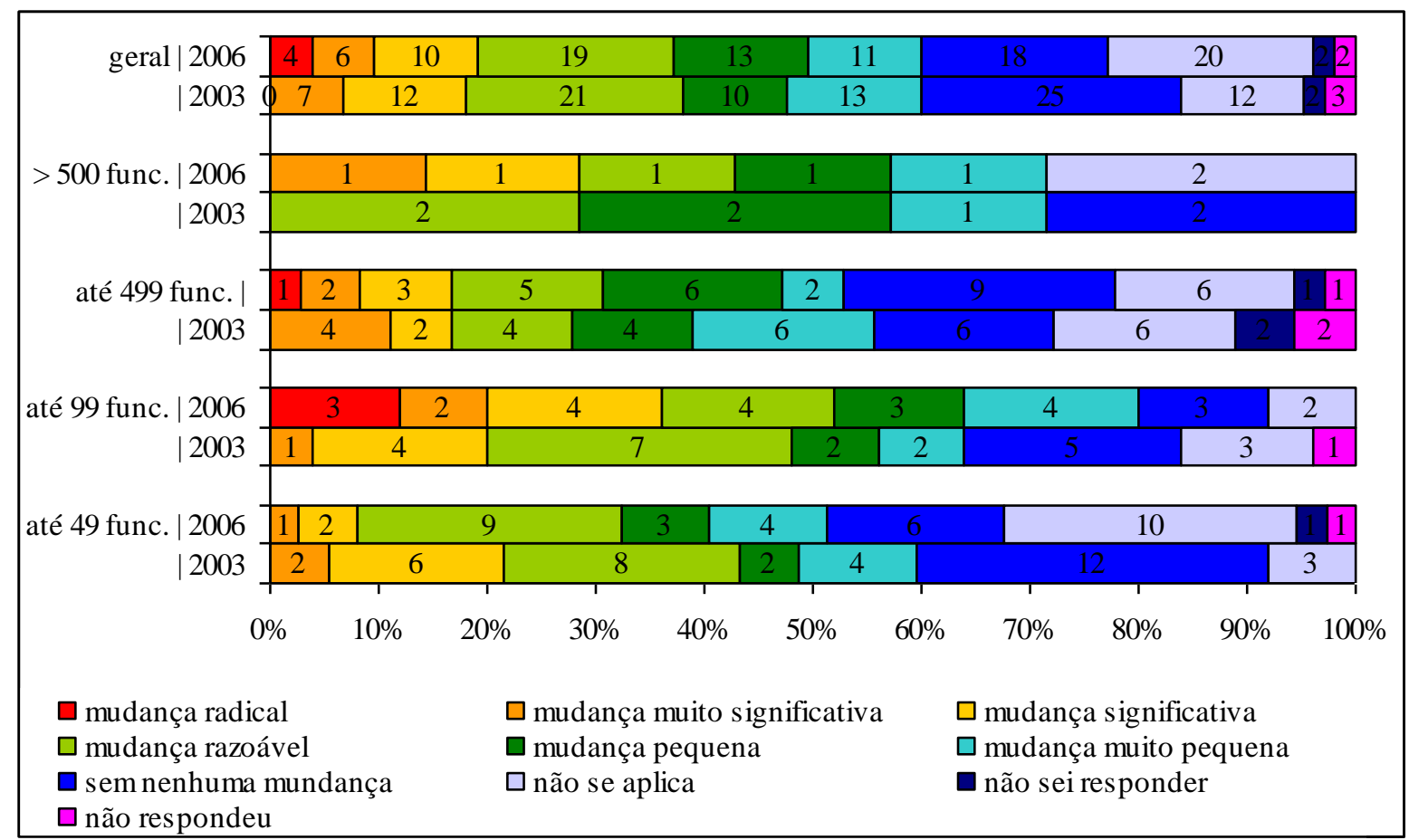

As respostas com relação ao projeto de processos produtivos (vide Figura 3) seguiram um padrão muito próximo ao obtido para o projeto de produtos (apresentado na Figura 2), embora com intensidade menor para todos os portes de empresa. Isto talvez se deva ao fato de os próprios programas de projeto auxiliado por computador (Computer Aided Design - CAD) serem voltados, na sua grande maioria, para o projeto de produtos. Poucas são as ferramentas de software dedicadas ao projeto de processos, com possibilidade de simulação de capacidade produtiva, identificação de gargalos e outras características importantes na definição de como produzir alguma coisa.

Como foi visto na revisão teórica, a simulação em computador pode substituir protótipos reais, encurtando os tempos envolvidos no projeto e reduzindo seus custos. As surveys continham uma pergunta sobre a intensidade de uso de abordagens de projeto que visam a simular em computador as diversas etapas do ciclo de vida de um projeto. Percebe-se no gráfico da Figura 4 que as empresas de maior porte dão mais atenção a esta possibilidade que as pequenas. Isto ocorre, 
provavelmente, em função do elevado custo das ferramentas de software que proporcionam este tipo de funcionalidade e/ou da exigência de conhecimento de recursos avançados destes programas de computador, que estão além das possibilidades de empresas de pequeno porte.

Figura 3 - Percepção de mudança ocasionada pela Internet e outras TI no projeto de processos

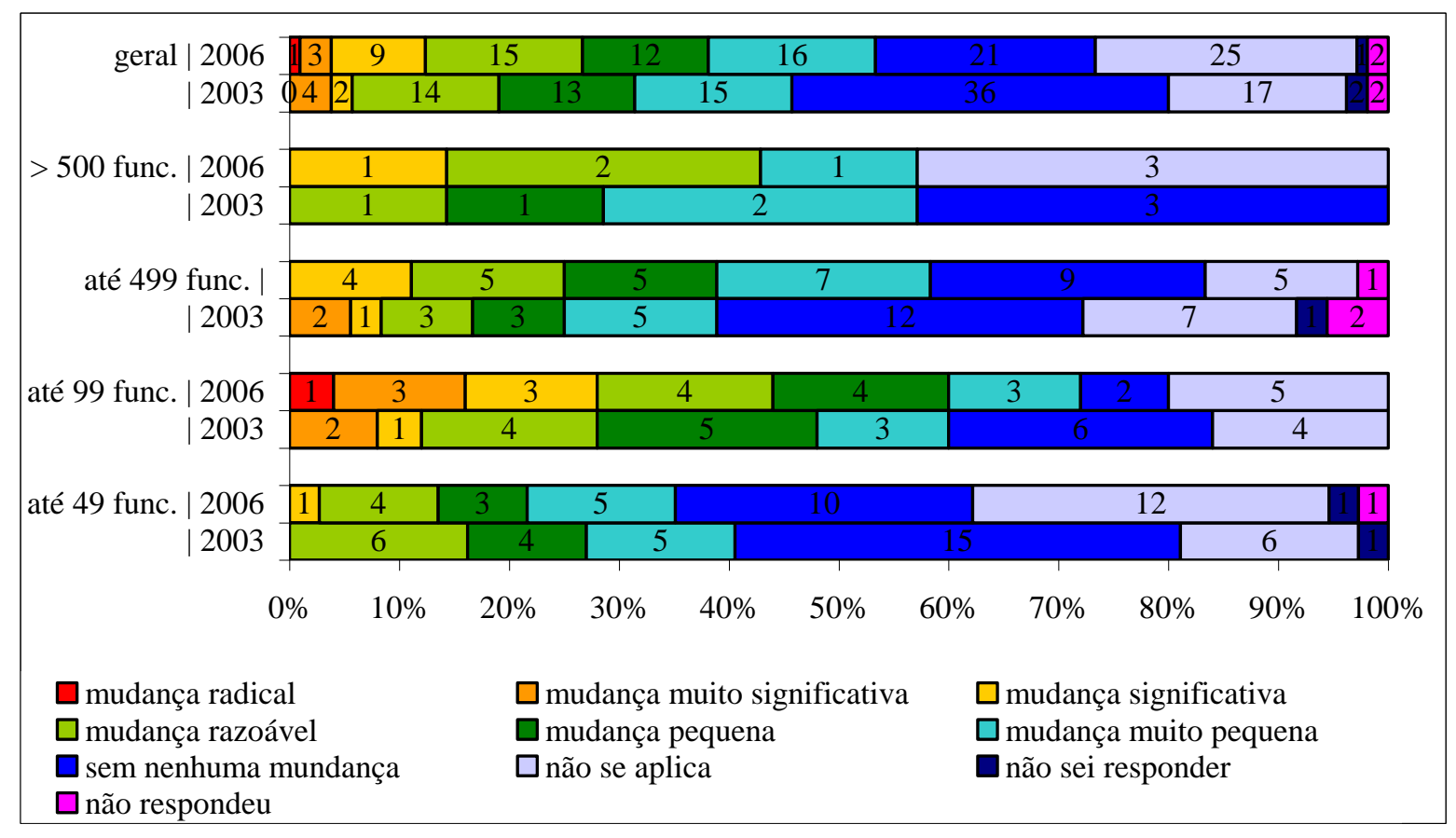

Também é interessante observar o que parece ser uma tendência de ampliação da intensidade de uso de técnicas de projeto baseado em simulação computacional ao longo do tempo, já que as barras relativas a 2006 apresentam maior densidade na extremidade "é fundamental para o negócio/usamos muito" do que as barras relacionadas a 2003, na Figura 4.

Figura 4 - Percepção da intensidade de uso de projeto baseado em simulação 


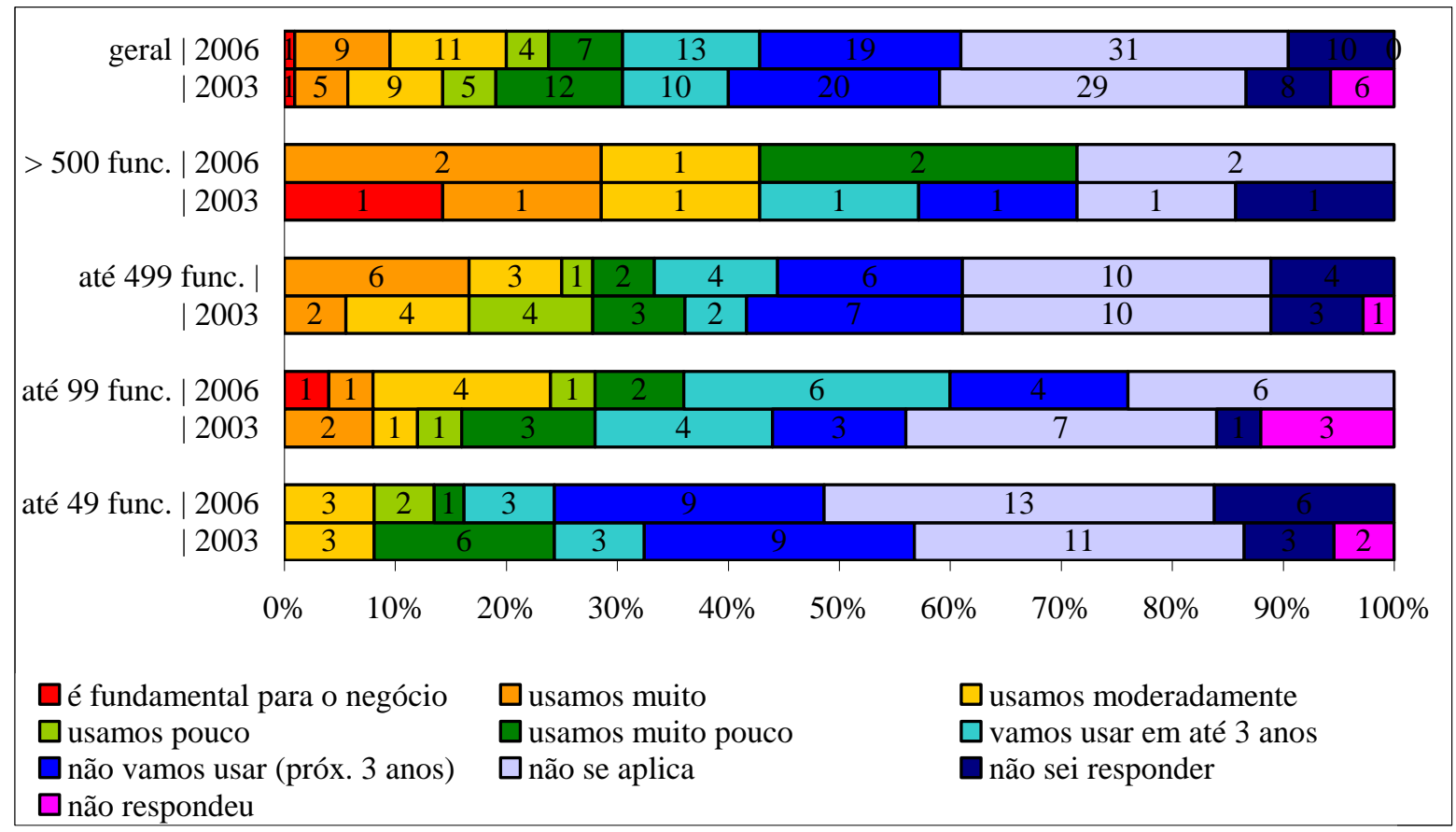

Um padrão semelhante ao obtido para projeto baseado em simulação (vide Figura 4) foi obtido para a utilização de prototipação virtual (vide Figura 5). Não poderia ser diferente, já que o projeto baseado em simulação depende da criação de prototipos virtuais que possam ser utilizados em substituição aos protótipos físicos, tradicionalmente utilizados para testar características de produtos antes de serem produzidos em escala industrial.

A utilização de realidade virtual, por sua vez, não apresentou expressividade que justificasse sequer a apresentação do gráfico a ela relacionado. Apenas 3 das 105 empresas pesquisadas afirmam, na survey de 2006/2007 utilizar simulações de computador que proporcionem sensações visuais, auditivas e táteis em suas atividades de projeto, a ponto de considerá-las muito importantes ou fundamentais para o seu negócio. Relevante com relação a esta questão é o fato que em 2003/2004, nenhuma empresa tinha esta percepção. Naquela época, apenas 5 empresas afirmaram que pretendiam começar a utilizar a técnica ao longo dos próximos 3 anos. Onze parecem tê-lo feito, a julgar pelas respostas ao questionário de 2006/2007 em que outras 13 empresas afirmam que pretendem começar a usar realidade virtual em seus projetos até 2010.

Figura 5 - Percepção da intensidade de uso de prototipação virtual 


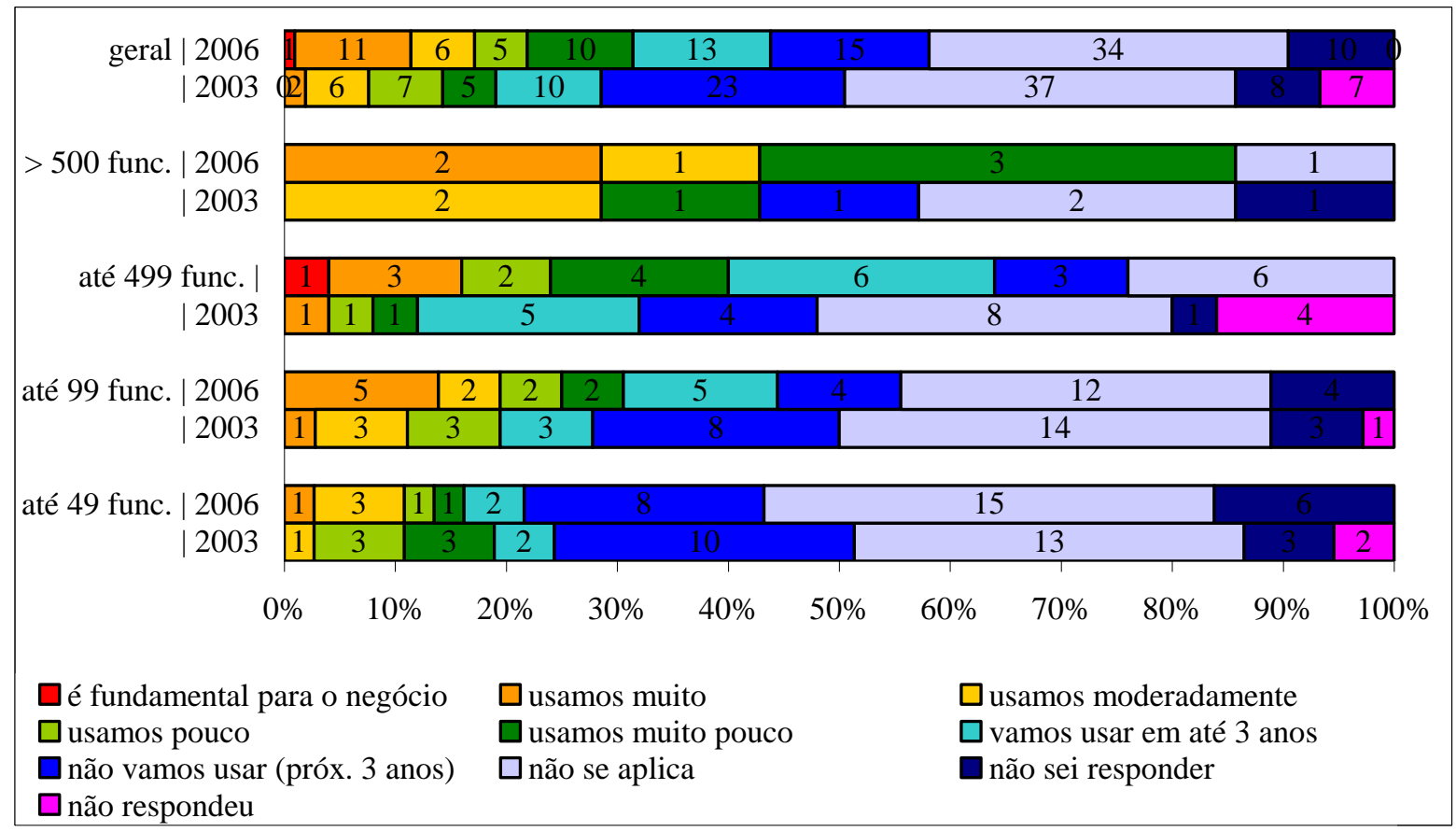

Por fim, as empresas foram questionadas sobre o uso de ferramentas que permitam a realização e a gestão do trabalho colaborativo de uma equipe de pessoas que se encontram fisicamente dispersas. Os resultados, embora indiquem utilização tímida do recurso (vide Figura 6) parecem apontar para uma tendência no sentido do avanço de utilização, que precisa ser confirmada por estudos futuros, uma vez que os níveis de utilização atual são muito baixos.

Figura 6 - Percepção da intensidade de uso de workflow e técnicas de trabalho colaborativo

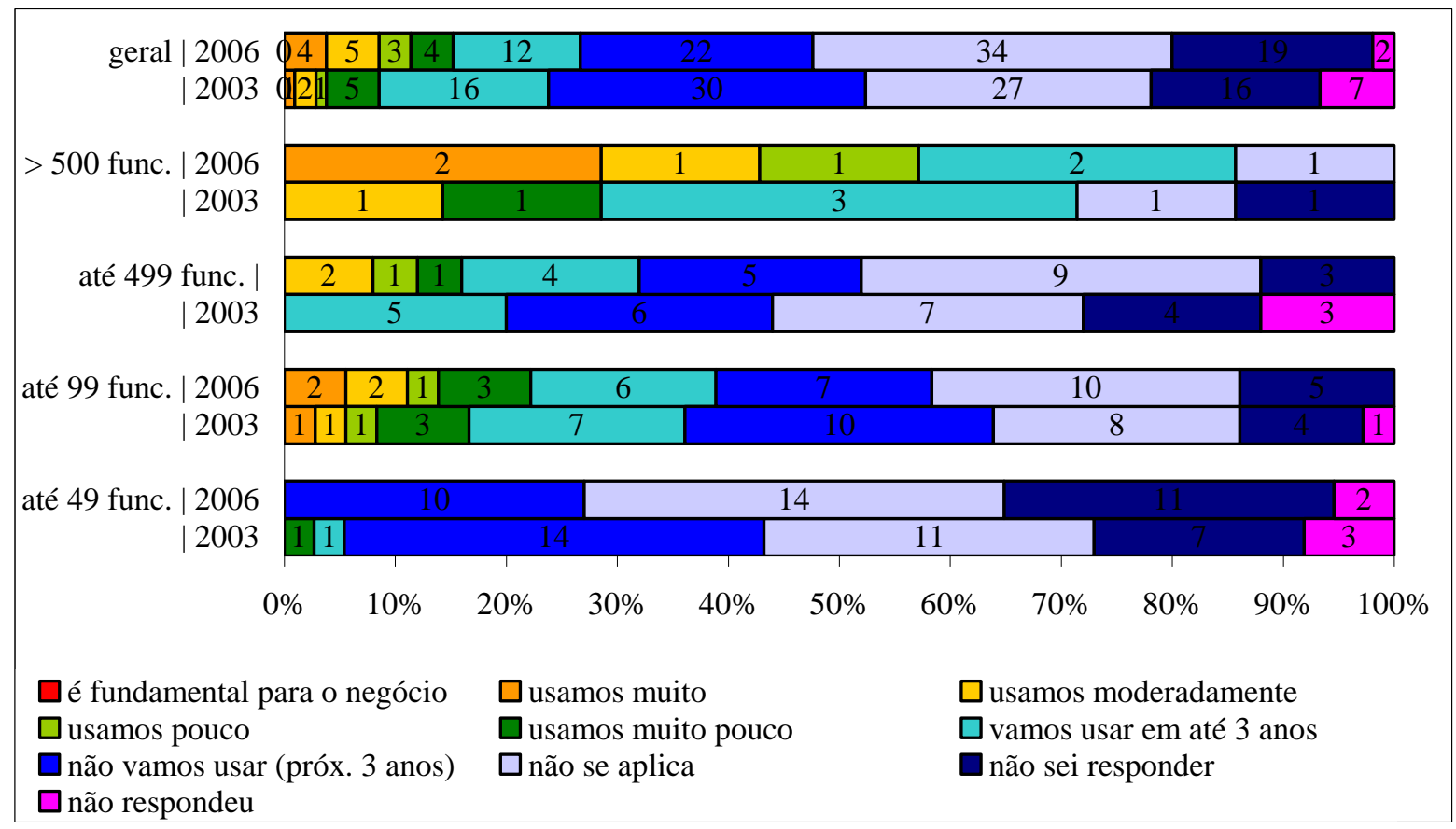


Com relação aos dados da Figura 6, chama atenção ainda o fato de que na survey de 2006/2007 diminuiu o percentual de empresas que não pretende utilizar ferramentas de workflow nos próximos 3 anos. Por outro lado, aumentou o número de respondentes que agora afirmam que a ferramenta não se aplica aos propósitos ou necessidades da empresa. Como isto acontece em paralelo a um aumento da utilização, pode refletir uma melhor compreensão dos potenciais benefícios das ferramentas de workflow e das circunstâncias em que elas podem contribuir com o bom desempenho de uma equipe de trabalho.

A escolha do intervalo de tempo de 3 anos entre as duas pesquisas teve o propósito de verificar se expectativas do período anterior haviam se confirmado. Afinal, algumas perguntas do questionário (especialmente aquelas cujas respostas foram expressas nas Figuras 4 a 6) incluíam a possibilidade de o respondente indicar se a empresa, no caso de ainda não utilizar uma dada ferramenta ou prática, pretendia fazê-lo nos próximos 3 anos. Os autores tinham especial curiosidade em saber de que forma evoluiria o cenário com relação às "intenções de uso futuro", já que pretender fazer alguma coisa, não envolve alocar recursos para que isto ocorra, o que torna muito mais fácil prever do que de fato fazer. Havia uma expectativa de que ao menos parte das intenções de uso não se confirmasse. O que se percebeu na análise, contudo, foi que, embora em alguns casos os respondentes de 2003/2004 tenham realmente sido otimistas e previsto avanços maiores do que os concretizados, isto não representou a regra. Em diversas situações a adoção das novas ferramentas se deu em ritmo até mais rápido do que o esperado, como no caso do uso de prototipação virtual. Observe-se que, na Figura 5, não há intersecção entre as caixinhas azuis claras para as respostas à pesquisa de 2003/2004 e de 2006/2007 (com exceção das empresas de muito pequeno porte).

\section{Conclusões}

A survey é uma ferramenta muito útil na obtenção de dados para análise em pesquisas científicas, principalmente no caso de projetos de escopo mais amplos, desenvolvidos com o objetivo de se obter uma compreensão geral do fenômeno estudado. Este artigo tratou de uma das diversas áreas em que a Internet pode contribuir com a mudança da forma de se fazer as coisas na indústria. $\mathrm{O}$ fato de ter se baseado em duas surveys com conteúdo idêntico, aplicadas às mesmas empresas com um intervalo de tempo pré-determinado, possibilitou que se analisasse também o componente temporal, tão importante quando se discute a adoção de novas ferramentas ou práticas.

Mas, se por um lado a survey tem esta característica de possibilitar a obtenção de um grande volume de dados sobre um número elevado de empresas, normalmente obtidas com um esforço reduzido, se comparado a outros métodos, por outro lado, em determinadas circunstâncias os dados 
coletados não são suficientes para possibilitar o aprofundamento da análise, exigindo que os pesquisadores lancem mão de outras ferramentas metodológicas para avançarem em suas conclusões. $\mathrm{O}$ fato de a coleta de dados para este estudo ter se restringido às duas surveys, não tendo sido complementada por outras técnicas que permitam triangulação, representa, ao mesmo tempo, na visão dos autores, a principal limitação do trabalho e uma rica fonte de possíveis trabalhos futuros. Diversas questões foram indicadas, ao longo da análise, como carentes de aprofundamento que o procedimento metodológico adotado era incapaz de permitir. Cada uma delas pode ser explorada individualmente, por meio de estudos de caso ou entrevistas com respondentes específicos que possam auxiliar no seu esclarecimento.

Os autores consideram que os resultados obtidos representam evidência forte do avanço da utilização pela indústria de São Paulo das ferramentas de projeto discutidas neste artigo e das mudanças trazidas pela adoção da Internet para este setor, embora indiquem também que ainda existe um grande potencial de crescimento, principalmente nas empresas de menor porte.

\begin{abstract}
This paper deals with the way manufacturing organizations use the Internet and other information technologies for design activities. The authors surveyed 105 companies in the state of Sao Paulo, Brazil, at two different moments in time: November 2003 and November 2006. In both situations respondents were asked about the impact of the Internet on the way they carried out design activities. The collected data was tabulated and analyzed, providing a better understanding of the extent to which Brazilian manufacturers are using the Internet and other IT in such activities. Results show that there is a trend towards using the new technology more intensively, but that there is still a lot to be done in order to achieve its full potential.
\end{abstract}

Key-words: Internet, virtual prototyping, virtual reality, collaborative work.

\title{
Referências
}

BAPAT, V. Explaining virtues of virtual manufacturing. InTech, v.49, n. 11, p. 76, Nov, 2002.

Boswell, B. Time to market, 1998. Disponível em: http://www.lionhrtpub.com/ee/ee-spring98/boswell.html. Acesso em: 26/02/2007.

CARMODY, S. Boeing plans virtual everything before 7E7 rollout. Machine Design, v. 75, n. 23, p. 22 , Dec 11, 2003. DEVIPRASAD, T. e KESAVADAS, T. Virtual prototyping of assembly components using process modeling. Journal of Manufacturing Systems, v.22, n. 1, p. 16-27, 2003.

\section{crossef}

DuARte, A. L. D. C. M. e BARberato, E. A evolução das ferramentas no desenvolvimento de novos produtos como fator de competitividade. In: Simpósio de Administração da Produção, Logística e Operações Industriais, 6o., São Paulo. Anais eletrônicos. POI-FGV, 2003. p. 1 CD-ROM.

ERA. Developing and building the leader - a look from inside the Embraer 170 program: European Regions Airline Association, 2002. Disponível em: http://www.eraa.org/system/id.asp?intid=787. Acesso em: 31/01/2003. 
FORD, D. N. e STERMAN, J. D. Overcoming the 90\% syndrome: iteration management in concurrent development projects, 1999. Disponível em: http://ceprofs.tamu.edu/dford/DNF\%20Profesional/Overcoming90SyndrCERAPUBLISHED.pdf. Acesso em: 26/02/2007.

Galina, S. V. R. e SAntos, A. C. D. Ambiente para auxílio ao trabalho cooperativo na engenharia simultânea. In: Encontro Nacional de Engenharia de Produção, 18o., Niterói. Anais eletrônicos. ABEPRO, 1998. p. 1 CD-ROM.

GEOFFrion, A. M. e KRISHNAN, R. Prospects for operations research in the e-business era. Interfaces, Mar-Apr, 2001.

Goldin, D. S., Venneri, S. L. e Noor, A. K. A new frontier in engineering. New York: Mechanical Engineering Magazine, $1998 . \quad$ Disponível em: http://www.memagazine.org/backissues/membersonly/february98/features/newfront/newfront.html. Acesso em: 26/02/2007.

JONS, O. P. Preservation and restoration of historic vessels in virtual environments. San Francisco: San Francisco National Maritime Park Association, 1997. Disponível em: http://www.maritime.org/conf/conf-jons.htm. Acesso em: 26/02/2007.

KENYON, H. S. Visualization center shapes the future. Signal, v. 58, n. 9, p. 65-68, May 2004, 2004.

KIRKMAN, B. L., et al. Five challenges to virtual team success: lessons from Sabre, Inc. Academy of Management Executive, v.16, n. 3, August, 2002.

cross ${ }^{\text {ref }}$

KroO, I. Computational-based design, 1996. Disponível em: http://aero.stanford.edu/ComputationalDesign.html. Acesso em: 26/02/2007.

Lebkowsky, J. A few points about online activism: Cybersociology Magazine, iss. 5, 1999. Disponível em: http://www.cybersociology.com/files/5 JonLebkowsky.html. Acesso em: 26/02/2007.

MCKenNA, R. Real time marketing. Harvard Business Review, Jul/Aug, 1995.

Moran, T. Virtual lab speeds testing, development of prototypes. Automotive News, v. 77, n. 6028, p. 32F, Mar 10, 2003, 2003.

OtтоSSON, S. Virtual reality in the product development process. Journal of Engineering Design, v.13, n. 2, p. 159, June, 2002.

cross ${ }^{\text {ref }}$

OZER, M. Using the Internet in new product development (managers at work). Research - Technology Management, p. 10-16, Jan/Feb, 2003.

PIRES, P. J. e PRATES, R. C. As estratégias organizacionais das indústrias de transformação localizadas na cidade industrial de Curitiba e a reestruturação produtiva no Brasil nos anos 90. In: Encontro da Associação Nacional dos Programas de Pós-Graduação em Administração, 28o., Atibaia, São Paulo. Anais eletrônicos. ANPAD, 2003. p. 1 CDROM.

RHEINGOLD, H. The virtual community: homesteading on the electronic frontier. Cambridge, Mass.: MIT Press, 2000. $447 \mathrm{p}$.

SHIFRIN, C. New Embraer family maintenance; extensive parts commonality and maintenance-friendly features distinguish the new Embraer 170 and 190 families. Overhaul \& Maintenance, v. 10, n. 3, p. 37, Apr, $2004,2004$.

ThOMKe, S. e HIPPEL, E. v. Customers as innovators: a new way to create value. Harvard Business Review, v.80, n. 4, p. 74, Apr, 2002.

\section{Dados completos dos autores:}

\section{Alexandre Reis Graeml}

Centro Universitário Positivo / Universidade Tecnológica Federal do Paraná 
Mestrado em Administração / Departamento Acadêmico de Informática

Professor adjunto

Rua Chichorro Junior, 364 apt. 504 Curitiba - PR 80035-040

(41) 9909-9792 ou (41) 3352-4424

graeml@fulbrightweb.org

\section{Marie Anne Macadar}

Universidade Estadual do Rio Grande do Sul

Curso de Administração Hospitalar

Professor adjunto

Rua São Luís, 286 Santana, Porto Alegre - RS CEP 90620-170

(51) $3219-8124$

marie-macadar@uergs.edu.br

\section{João Mário Csillag}

Escola de Administração de Empresas de São Paulo

Departamento de Produção e Operações Industriais

Professor adjunto

Av. 9 de Julho, 2029 Sao Paulo-SP CEP 01313-902

(11) $287-0148$

csillag@fgvsp.br

Recebido para publicação em: 06/08/07

Aceito para publicação em: 03/09/07 